\title{
Transarterial embolization for pelvic hematoma following laparoscopic radical prostatectomy: A case report and review of the literature
}

\author{
TASUKU HIROSHIGE, MITSUNORI MATSUO, KOSUKE UEDA, MAKOTO NAKIRI, \\ KIYOAKI NISHIHARA and TSUKASA IGAWA \\ Department of Urology, Kurume University School of Medicine, Kurume, Fukuoka 830-0011, Japan
}

Received August 29, 2014; Accepted May 20, 2015

DOI: $10.3892 / \mathrm{ol} .2015 .3381$

\begin{abstract}
The present study reports a case of hemorrhage from branches of the right obturator artery following laparoscopic radical prostatectomy. On post-operative day 9 , the patient complained of lower abdominal pain, and the hemoglobin and hematocrit levels had decreased. Emergency computed tomography angiography showed a large pelvic hematoma suggesting active bleeding. Transarterial embolization (TAE) was performed using microcoils. There were no post-procedure complications. At 3 months post-surgery, using computed tomography, the pelvic hematoma was shown to have been absorbed. To the best of our knowledge, TAE for a hemorrhage from the obturator artery following laparoscopic prostatectomy has not previously been described. TAE is a safe and minimally invasive treatment compared with surgical intervention, and should be considered as a treatment for post-operative arterial hemorrhage.
\end{abstract}

\section{Introduction}

Prostate cancer is one of the most common malignancies of the urinary tract. Based on incidence and mortality data from several agencies, the American Cancer Society estimates that 233,000 new prostate cancer cases and 29,480 mortalities from prostate cancer are projected to occur in the United States in 2014 (1). Prostate cancer is a heterogeneous disease that varies in spectrum from tumors with a low risk of mortality to highly aggressive malignant disease (2). Newly diagnosed prostate cancer has been increasing in Japan, and is predicted to be the first or second most common cancer by 2020 (3). Although the

Correspondence to: Dr Tasuku Hiroshige, Department of Urology, Kurume University School of Medicine, 67 Asahimachi, Kurume, Fukuoka 830-0011, Japan

E-mail: tkkn19841220@yahoo.co.jp

Key words: laparoscopic radical prostatectomy, transarterial embolization age-adjusted mortality rate, which had rapidly increased up to $\sim 2,000$, began to reduce slightly in 2004 , the crude mortality rate has continued to rise gradually due to the ageing population (4). Radical prostatectomy has commonly been performed using an open retropubic approach for localized prostate cancer. However, in the past decade, with the development of laparoscopic and robotic techniques, laparoscopic radical prostatectomy (LRP) or robotic-assisted LRP (RALRP) has been widely accepted with the advantages of less invasiveness, shorter recovery, reduced blood loss, and improved visualization of the operative region compared to open techniques (5-7) Severe hemorrhage following prostatectomy is relatively rare, but is one of the serious complications. The current study presents a case in which arteriography with transarterial embolization (TAE) was beneficial for the treatment of severe hemorrhage following LRP.

\section{Case report}

In May 2013, a 70-year-old man first presented with lower urinary tract symptoms to the outpatient clinic of Kurume University Hospital, Fukuoka, Japan and was demonstrated to have an elevated the prostate-specific antigen (PSA) of $9.3 \mathrm{ng} / \mathrm{ml}$. In September 2013, subsequent transrectal ultrasound-guided biopsy of the prostate showed prostate adenocarcinoma, with Gleason Score 3+4=7 involving $30 \%$ of the bilateral lobes. According to the imaging and biopsy findings, the tumor was classified as cT2cN0M0. In December 2013, LRP and pelvic lymphadectomy were performed without nerve sparing bilaterally. Vesico-urethral anastomosis with continuous suture was conducted using 3-0 absorbable monofilament suture. The surgical duration was $183 \mathrm{~min}$ and the blood loss during the procedure was $580 \mathrm{~g}$. Early post-operative recovery was uneventful. Cystography showed no urinary leakage and the Foley catheter was removed on post-operative day 3.

On post-operative day 9 , the patient complained of lower abdominal pain. The hemoglobin $(\mathrm{Hb})$ level decreased from 11.4 to $7.3 \mathrm{~g} / \mathrm{dl}$ (normal range, 13.5-17.5 g/dl) and the hematocrit $(\mathrm{Ht})$ level decreased from 33.5 to $21.8 \%$ (normal range, 39.7-52.4\%). Four units of blood were transfused and emergent computed tomography angiography (CTA) showed a large pelvic hematoma, with extravasation of the contrast agent in 


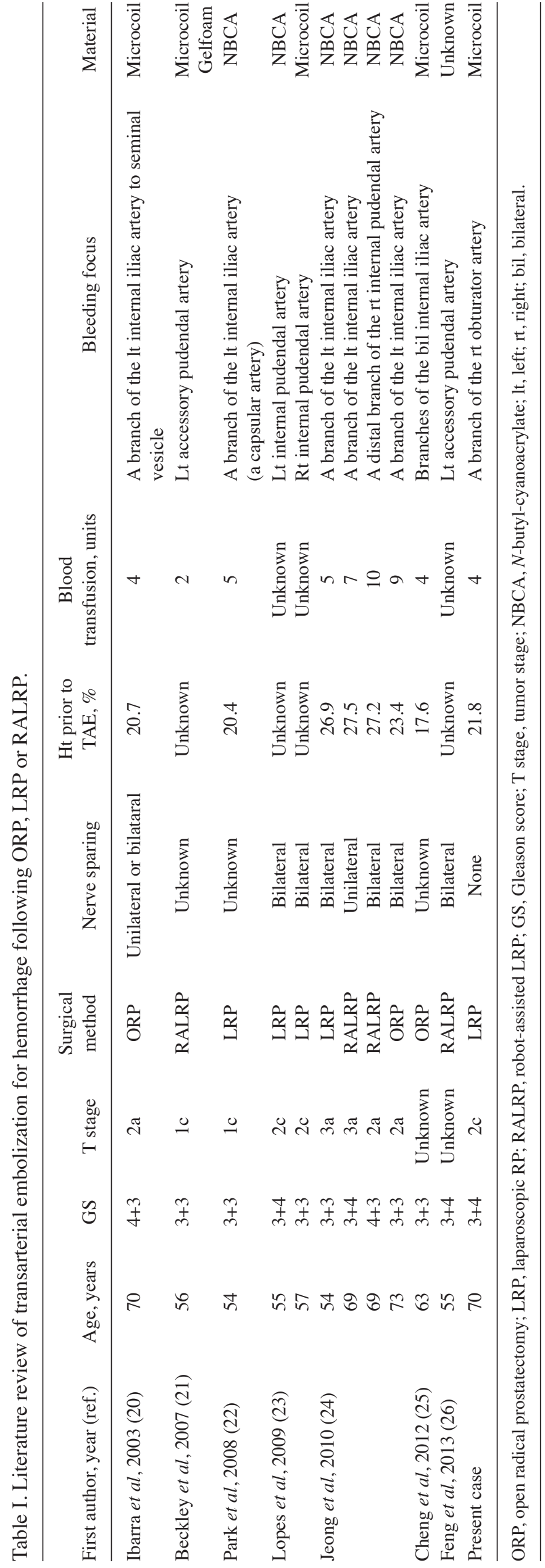

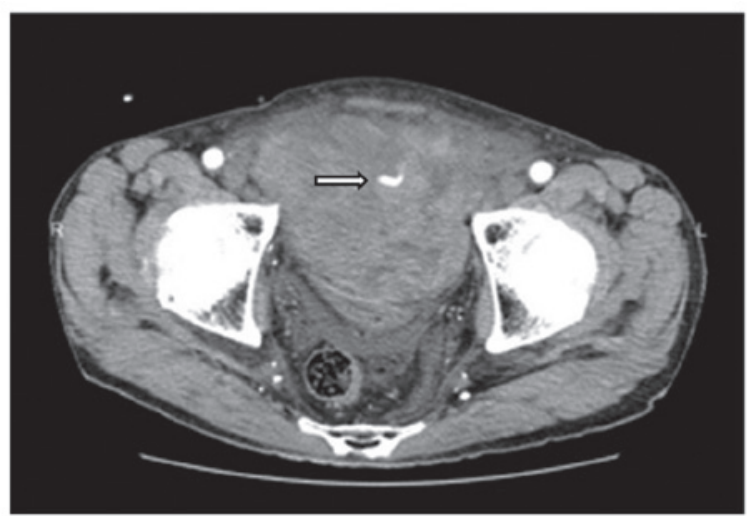

Figure 1. Computed tomography angiography showing a large pelvic hematoma and extravasation of the contrast agent in the hematoma.

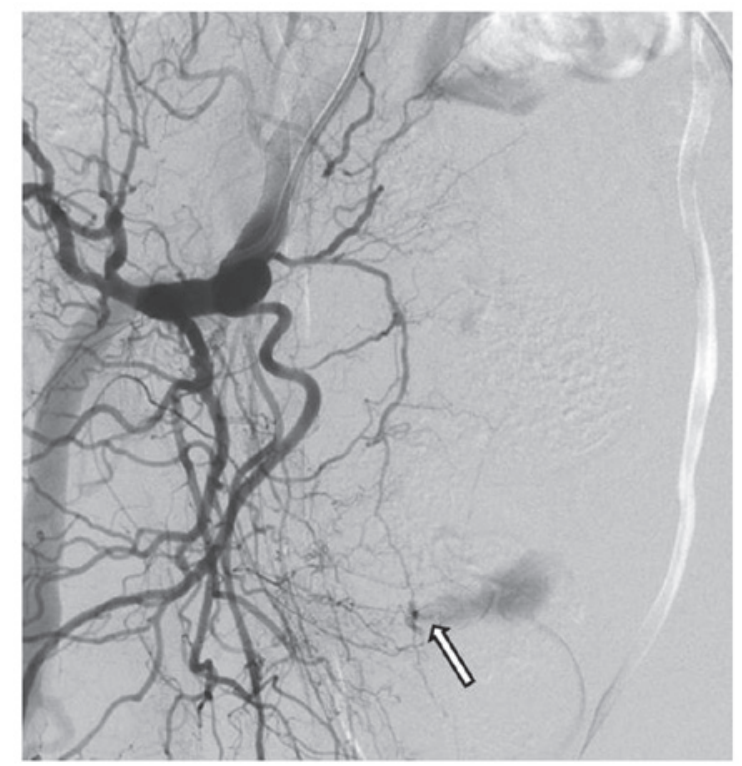

Figure 2. Digital subtraction angiography revealing active bleeding from a branch of the right obturator artery.

the hematoma, suggesting arterial bleeding. Digital subtraction angiography (DSA), performed via a transfemoral approach with selective catheterization of the two internal iliac arteries (Fig. 1), revealed active bleeding from a branch of the right obturator artery. We speculate that this branch may have been injured during pelvic lymphadectomy (PLND). Super selective catheterization of the bleeding vessel was performed using a microcatheter $(2.2 \mathrm{Fr} / 2.8 \mathrm{Fr})$ with a hydrophilic 0.016 -inch guidewire. Embolization was performed successfully using a platinum coil $(2 \times 10 \mathrm{~mm})$.

However, the $\mathrm{Hb}$ level remained at 7.0 to $8.0 \mathrm{~g} / \mathrm{dl}$ and follow-up CT revealed that the pelvic hematoma had increased in size. On post-operative day 16 , a second DSA procedure was performed, but no arterial bleeding was revealed. Following the second DSA procedure, the $\mathrm{Hb}$ and $\mathrm{Ht}$ levels improved and the patient was discharged on post-operative day 36. At 3 months post-surgery, the pelvic hematoma was shown to have been absorbed on computed tomography scans. The patient is currently mildly incontinent, with a PSA level of $0.03 \mathrm{ng} / \mathrm{ml}$. 


\section{Discussion}

LRP was first described by Schuessler et al (8) and Raboy et al (9) in 1997. The surgical procedure was established in 1999 by Guillonneau et al (10). A large body of literature has shown that LRP and RALRP are an effective option and the standard surgical treatment for localized prostate cancer, as these approaches are minimally invasive compared with open radical prostatectomy (ORP) and achieve a level of cancer control equivalent to that following ORP (5-7,10-13). Severe post-operative hemorrhage following radical prostatectomy has been reported in 0.5 to $1.6 \%$ of cases, according to a range of definitions $(14,15)$. A meta-analysis of the incidence of complications showed that pelvic hematoma was significantly less frequent following RALRP compared with ORP. In addition, the study showed that there is no significant difference in the frequency between LRP and ORP (16).

Severe hemorrhage following radical prostatectomy was first described by Foss in 1923 (17). The incidence rates of intraoperative and post-operative hemorrhage have decreased since Reiner and Walsh (18) described the anatomy of the dorsal venous complex and a method for early hemorrhage control during radical prostatectomy. Hemorrhage following radical prostatectomy is mainly of venous origin. Arterial hemorrhage is uncommon. Compression of the retropubic space with tissue-to-tissue contact leads to rapid resolution in cases of venous hemorrhage. By contrast, surgical intervention is recommended for arterial hemorrhage. In a retrospective study of 7 cases with serious hemorrhage among 1,350 cases treated with ORP, Hedican and Walsh (14) suggested that evacuation of the pelvic hematoma decreased the likelihood of bladder neck contracture and incontinence. In an examination of post-operative and quality of life outcomes in patients with major hemorrhage following ORP that was managed by reoperation or observation, Kaufman and Lepor (15) reported that reoperation facilitated the healing of the vesico-urethral anastomosis and removal of the urinary catheter.

TAE has become an increasingly common treatment for life-threatening hemorrhage from various bleeding sites. TAE has the advantages of a rapid recovery, short hospital stay and early resumption of physical activities compared with surgical intervention (19). To the best of our knowledge, 12 patients, including the present case, have been reported thus far with post-operative hemorrhage treated by TAE (Table I) (20-26). In this previously reported literature, 3 patients underwent ORP, 4 underwent RALRP and 5 underwent LRP. Almost all cases, with the exception of the present case, underwent bilateral or unilateral nerve sparing. CTA revealed active bleeding in all cases, and extravasation in CTA was important for discriminating between venous and arterial hemorrhage. The bleeding focus was frequently the internal pudendal or accessory pudendal artery. However, in the present case, the bleeding focus was a branch of the obturator artery which may have been injured during PLND. Bratt et al (27) recorded 4 cases of post-operative pelvic hematoma among 156 patients treated with PLND following radical prostatectomy. TAE for hemorrhage from the obturator artery following laparoscopic prostatectomy has not been described previously.
Materials for use in embolization include coils, polyvinyl alcohol particles, gelatin sponge (Gelfoam), and $N$-butyl-cyanoacrylate (NBCA) (28). The major advantages of microcoils are the absence of movement to a peripheral blood vessel and a lower risk of recanalization compared with other materials. However, the small diameters of distal branches usually do not allow the use of microcoils. Collateralization is a further possible disadvantage of microcoil embolization and may lead to the persistent flow of blood into the vascular region of the embolized vessel, thus decreasing the therapeutic efficacy (29). Gelfoam has commonly been used for hemorrhage from small branches in cases in which microcoils could not be used or were unavailable, but the temporary nature of Gelfoam leaves a risk of recanalization. NBCA has been used most commonly in previous studies $(24,26)$. NBCA is administered in liquid form prior to polymerization, and is generally mixed with iodized oil to minimize the exothermic reaction of NBCA, which delays and controls the polymerization time. This feature is beneficial in the occlusion of small vessels (29).

With regard to post-operative urinary incontinence, 6 cases from the literature regained excellent urinary continence within a 6 -month follow-up period, while only 2 patients experienced mild incontinence. These continence results are not inferior to those of previous studies of surgical intervention. In the present case, the patient experienced a certain degree of stress urinary continence at the 3-month follow-up, but it is likely that the incontinence will improve with time.

In summary, the current study presented a case in which TAE was performed for pelvic hematoma following LRP. Arterial hemorrhage following prostatectomy is relatively rare, but is one of the serious complications. It may be concluded that TAE for arterial hemorrhage following radical prostatectomy is a safe and minimally invasive treatment compared with surgical intervention. Moreover, it may be advantageous with regard to urinary incontinence.

\section{References}

1. Siegel R, Ma J, Zou Z and Jemal A: Cancer statistics, 2014. CA Cancer J Clin 64: 9-29, 2014.

2. Teloken C, Da Ros CT, Caraver F, Weber FA, Cavalheiro AP and Graziottin TM: Low serum testosterone levels are associated with positive surgical margins in radical retropubic prostatectomy: Hypogonadism represents bad prognosis in prostate cancer. J Urol 174: 2178-2180, 2005.

3. Katanoda K, Hori M, Matsuda T, Shibata A, Nishino Y, Hattori M, Soda M, IokaxA, Sobue T and Nishimoto H: An updated report on the trends in cancer incidence and mortality in Japan, 1958-2013. Jpn J Clin Oncol 45: 390-401, 2015.

4. Onozawa M, Hinotsu S, Tsukamoto T, Oya M, Ogawa O, Kitamura T, Suzuki K, Naito S, Namiki M, Nishimura K, Hirao Y and Akaza H: Recent trends in the initial therapy for newly diagnosed prostate cancer in Japan. Jpn J Clin Oncol 44: 969-981, 2014.

5. Tooher R, Swindle P, Woo H, Miller J and Maddern G: Laparoscopic radical prostatectomy for localized prostate cancer: A systematic review of comparative studies. J Urol 175: 2011-2017, 2006.

6. Ferronha F, Barros F, Santos VV, Ravery V and Delmas V: Is there any evidence of superiority between retropubic, laparoscopic or robot-assisted radical prostatectomy? Int Braz J Urol 37: 146-158, 2011.

7. Akand M, Celik O, Avci E, Duman I and Erdogru T: Open, laparoscopic and robot-assisted laparoscopic radical prostatectomy: Comparative analysis of operative and pathologic outcomes for three techniques with a single surgeon's experience. Eur Rev Med Pharmacol Sci 19: 525-531, 2015. 
8. Schuessler WW, Schulam PG, Clayman RV and Kavoussi LR: Laparoscopic radical prostatectomy: Initial short-term experience. Urology 50: 854-857, 1997.

9. Raboy A, Ferzli G and Albert P: Initial experience with extraperitoneal endoscopic radical retropubic prostatectomy. Urology 50: 849-853, 1997.

10. Guillonneau B, Cathelineau X, Barret E, Rozet F and Vallancien G: Laparoscopic radical prostatectomy: Technical and early oncological assessment of 40 operations. Eur Urol 36 : 14-20, 1999.

11. Greco F, Wagner S, Hoda MR, Kawan F, Inferrera A, Lupo A, Reichelt O, Jurczok A, Hamza A and Fornara P: Laparoscopic vs open retropubic intrafascial nerve-sparing radical prostatectomy: surgical and functional outcomes in 300 patients. BJU Int 106: $543-547,2010$

12. Drouin SJ, Vaessen C, Hupertan V, Comperat E, Misraï V, Haertig A, Bitker MO, Chartier-Kastler E, Richard F and Rouprêt M: Comparison of mid-term carcinologic control obtained after open, laparoscopic and robot-assisted radical prostatectomy for localized prostate cancer. World J Urol 27: 599-605, 2009.

13. Moran PS, O'Neill M, Teljeur C, Flattery M, Murphy LA, Smyth G and Ryan M: Robot-assisted radical prostatectomy compared with open and laparoscopic approaches: A systematic review and meta-analysis. Int J Urol 20: 312-321, 2013.

14. Hedican SP and Walsh PC: Postoperative bleeding following radical retropubic prostatectomy. J Urol 152: 1181-1183, 1994.

15. Kaufman JD and Lepor H: Reoperation versus observation in men with major bleeding after radical retropubic prostatectomy. Urology 66: 561-565, 2005.

16. Tewari A, Sooriakumaran P, Bloch DA, Seshadri-Kreaden U, Hebert AE and Wiklund P: Positive surgical margin and perioperative complication rates of primary surgical treatments for prostate cancer: A systematic review and meta-analysis comparing retropubic, laparoscopic and robotic prostatectomy. Eur Urol 62: 1-15, 2012.

17. Foss HL: The control of hemorrhage following prostatectomy. Ann Surg 78: 802-805, 1923

18. Reiner WG and Walsh PC: An anatomical approach to the surgical management of the dorsal vein and Santorini's plexus during radical retropubic surgery. J Urol 121: 198-200, 1979.
19. Beaujeux R, Saussine C, al-Fakir A, Boudjema K, Roy C, Jacqmin D and Bourjat P: Superselective endo-vascular treatment of renal vascular lesions. J Urol 153: 14-17, 1995.

20. Ibarra R, Magee C, Ferral H and Thompson IM: Post-prostatectomy bleeding managed by endovascular embolization. J Urol 169: 276-277, 2003.

21. Beckley I, Patterson B, Hamaday M, Vale J and Hrouda D: Case report: Delayed hemorrhage from an accessory internal pudendal artery pseudoaneurysm after robotic radical prostatectomy: Successful management with ct angiography and embolization. J Endourol 21: 923-925, 2007.

22. Park YH, Lee JH and Kim HH: Severe bleeding after laparoscopic radical prostatectomy: Successful management with transarterial embolization. J Endourol 22: 2687-2689, 2008.

23. Lopes RI, Mitre AI, Rocha FT, Piovesan AC, da Costa OF and Karakhanian W: Case report: Late recurrent hematuria following laparoscopic radical prostatectomy may predict internal pudendal artery pseudoaneurysm and arteriovenous fistula. J Endourol 23: 297-299, 2009.

24. Jeong CW, Park YH, Ku JH, Kwak C and Kim HH: Minimally invasive management of postoperative bleeding after radical prostatectomy: Tvransarterial embolization. J Endourol 24: 1529-1533, 2010

25. Cheng S, Xu L, Li G, Chen Y, Hu H, Zhang Z and Ding G: Superselective internal iliac arterial embolization for severe hemorrhage following radical prostatectomy. Oncol Lett 4: 521-523, 2012.

26. Feng T, Patel HD and Allaf ME: Pudendal artery pseudoaneurysm after robot-assisted laparoscopic radical prostatectomy. Urology 81: e5-e6, 2013.

27. Bratt O, Elfving P, Flodgren P and Lundgren R: Morbidity of pelvic lymphadenectomy, radical retropubic prostatectomy and external radiotherapy in patients with localised prostatic cancer. Scand J Urol Nephrol 28: 265-271, 1994.

28. Fratezi AC, Martins VM, Pereira Porta RM, Prado MA, Prota R, Caldas JG and Cerri G: Endovascular therapy for priapism secondary to perineal trauma. J Trauma. 50: 581-584, 2001.

29. Wang MQ, Duan F, Liu FY, Wang ZJ and Song P: Treatment of symptomatic polycystic liver disease: Transcatheter super-selective hepatic arterial embolization using a mixture of NBCA and iodized oil. Abdom Imaging 38: 465-473, 2013. 